\title{
Brincando, investigando e aprendendo ciências nos anos iniciais do ensino fundamental com brincadeiras científicas investigativas
}

Wagner da Cruz Seabra Eiras wagner.seabra@ifsudestemg.edu.br orcid.org/0000-0002-3879-3638 Instituto Federal do Sudeste de Minas
Gerais (IF SUDESTE MG), Juiz de Fora, Minas Gerais, Brasil

Paulo Henrique Dias Menezes paulo.menezes@ufj.edu.br orcid.org/0000-0002-3008-9830 Universidade Federal de Juiz de Fora
(UFJF), Juiz de Fora, Minas Gerais, Brasil

Cristhiane Carneiro Cunha Flôr criscunhaflor@gmail.com orcid.org/0000-0002-9175-1859 Universidade Federal de Juiz de Fora (UFJF), Juiz de Fora, Minas Gerais, Brasil

\section{RESUMO}

Neste artigo apresentamos parte de uma pesquisa mais ampla de doutorado que analisou a participação de crianças em brincadeiras científicas investigativas $(\mathrm{BCl})$ realizadas durante as aulas de Ciências de uma turma de quinto ano do Ensino Fundamental. As brincadeiras científicas investigativas ( $\mathrm{BCl}$ ) são atividades nas quais são investigados os princípios de funcionamento de brinquedos científicos, construídos com materiais de baixo custo e de fácil aquisição, a fim de explorar fenômenos físicos na Educação em Ciências no Ensino Fundamental. Este estudo trata de um recorte da pesquisa com o objetivo específico de analisar a participação de uma das crianças em uma $\mathrm{BCl}$ que teve como foco um brinquedo intitulado disco flutuante. A pesquisa foi desenvolvida numa abordagem qualitativa, na perspectiva histórico-cultural, e os dados foram obtidos pela observação, conversas informais com a aluna e a professora de Ciências, além de registros audiovisuais da $\mathrm{BCl}$ analisada. Os resultados obtidos mostram que a $\mathrm{BCl}$ incentivou a aluna a exercer o protagonismo autônomo na atividade por meio de ações autônomas de brincar, investigar, enunciar perguntas, hipóteses ou explicações inusitadas, de idealizar e construir coisas, e de socializar suas ideias com outras pessoas. Com isso, evidenciamos a importância das $\mathrm{BCl}$ enquanto possibilidade de os professores de Ciências dos anos iniciais do Ensino Fundamental promoverem atividades que incentivem o protagonismo autônomo das crianças, entendendo que assumir o papel principal de um acontecimento com autonomia e responsabilidade é fundamental na formação do cidadão contemporâneo.

PALAVRAS-CHAVE: Brincadeira Científica Investigativa. Educação em Ciências. Anos iniciais do Ensino Fundamental. Protagonismo autônomo. 


\section{INTRODUÇÃO}

A importância da brincadeira na formação de uma criança foi bastante elucidada por Vigotski (2008), segundo o qual, para a criança na idade pré-escolar ${ }^{1}$ a brincadeira surge "[...] como uma realização imaginária e ilusória de desejos irrealizáveis" (p. 25). Quando uma criança deseja dirigir um carro, mas ainda não pode, ela se imagina segurando um volante, movimentando suas mãos ora para um lado, ora para outro, além de emitir sons característicos de um automóvel em movimento. Ou seja, quando uma criança se sente incapaz de vivenciar uma situação real, ela brinca de faz-de-conta com aquilo que gostaria de fazer na realidade, servindo de atividade-guia para o seu aprendizado e desenvolvimento. Ao criar uma situação imaginária, a criança "desenvolve seu pensamento abstrato, aprende regras sociais, educa a sua vontade" (PRESTES, 2011, p. 4).

De acordo com Vigotski (2008), a criação de uma situação imaginária provoca a emancipação da criança frente às limitações reais, ou seja, na brincadeira a criança tem liberdade para imaginar e agir, sem se sentir insuficiente.

\footnotetext{
A brincadeira cria uma zona de desenvolvimento iminente na criança. $\mathrm{Na}$ brincadeira, a criança está sempre acima da média da sua idade, acima de seu comportamento cotidiano; na brincadeira, é como se a criança estivesse numa altura equivalente a uma cabeça acima da sua própria altura. A brincadeira em forma condensada contém em si, como na mágica de uma lente de aumento, todas as tendências do desenvolvimento; ela parece tentar dar um salto acima do seu comportamento comum. [...] A ação num campo imaginário, numa situação imaginária, a criação de uma intenção voluntária, a formação de um plano de vida, de momentos volitivos - tudo isso surge na brincadeira, colocando-a num nível superior de desenvolvimento, elevandoa para a crista da onda e fazendo dela a onda decúmana do desenvolvimento na idade pré-escolar, que se eleva das águas mais profundas, porém relativamente calmas (VIGOTSKI, 2008, p. 35).
}

Além disso, nas brincadeiras a criança aprende a agir submetendo-se às regras que, por vezes, estimulam a recusa daquilo que deseja, como, por exemplo, em uma brincadeira de apostar corrida em que as crianças têm dificuldade de controlar a ação impulsiva de iniciar a corrida antes da ordem para a partida, pois "a submissão às regras e a recusa à ação impulsiva imediata, na brincadeira, é o caminho para a satisfação máxima" (VIGOTSKI, 2008, p. 32).

Portanto,

[...] a brincadeira dá a criança uma nova forma de desejos, ou seja, ensinara a desejar, relacionando o desejo com o 'eu' fictício, ou seja, com o papel da brincadeira e a sua regra. Por isso, na brincadeira são possíveis as maiores realizações da criança que, amanhã, se transformarão em seu nível médio real, em sua moral (VIGOTSKI, 2008, p. 32-3).

De acordo com Leontiev (2017), uma atividade que auxilie no desenvolvimento da habilidade da criança em se submeter a uma regra, mesmo quando um estímulo direto a impele ao contrário, tem um importante papel no desenvolvimento da sua personalidade. Assim, é a partir das brincadeiras que se "[...] desenvolvem processos psíquicos que preparam o caminho da transição da criança para um novo e mais elevado nível de desenvolvimento" (LEONTIEV, 2017, p. 122). 
As brincadeiras são muito valorizadas no Estatuto da Criança e do Adolescente (ECA), em cujo capítulo II, artigo 16, inciso IV é explicitado que toda criança tem direito de desfrutar de jogos e brincadeiras, os quais deverão estar dirigidos para a educação, cabendo aos pais e professores a responsabilidade em promover o exercício desse direito (BRASIL, 2002).

Da mesma forma, nas Diretrizes Curriculares Nacionais Gerais para a Educação Básica (DCN) a brincadeira é considerada uma atividade muito importante, pois

[...] brincar dá à criança oportunidade para imitar o conhecido e para construir o novo, conforme ela reconstrói o cenário necessário para que sua fantasia se aproxime ou se distancie da realidade vivida, assumindo personagens e transformando objetos pelo uso que deles faz (BRASIL, 2013, p. 89).

Nessa perspectiva, os educadores do Ensino Fundamental, principalmente dos anos iniciais, são incentivados a utilizarem as brincadeiras na educação das crianças:

O Ensino Fundamental terá muito a ganhar se absorver da Educação Infantil a necessidade de recuperar o caráter lúdico da aprendizagem, particularmente entre as crianças de 6 (seis) a 10 (dez) anos que frequentam as suas classes, tornando as aulas menos repetitivas, mais prazerosas e desafiadoras e levando à participação ativa dos alunos (BRASIL, 2013, p. 121).

Por outro lado, apesar de a Base Nacional Comum Curricular (BNCC) valorizar o brincar na Educação Infantil, e nos vários componentes curriculares do Ensino Fundamental, a brincadeira é pouco explorada na área de Ciências da Natureza dessa etapa escolar. No texto da BNCC referente a essa área, o brincar é mencionado somente na afirmação sobre o interesse das crianças dos anos iniciais pela unidade temática Terra e Universo, já que "Os estudantes dos anos iniciais se interessam com facilidade pelos objetos celestes, muito por conta da exploração e valorização dessa temática pelos meios de comunicação, brinquedos, desenhos animados e livros infantis" (BRASIL, 2017, p. 326).

Em contrapartida, as atividades investigativas são amplamente contempladas na BNCC para a Educação Infantil e o Ensino Fundamental. De acordo com a BNCC, a área de Ciências da Natureza deve assegurar aos alunos do Ensino Fundamental o acesso à diversidade de conhecimentos científicos produzidos ao longo da história, necessitando que os alunos sejam "[...] estimulados e apoiados no planejamento e na realização cooperativa de atividades investigativas, bem como no compartilhamento dos resultados dessas investigações" (BRASIL, 2017, p. 320).

Nessa perspectiva,

O processo investigativo deve ser entendido como elemento central na formação dos estudantes, em um sentido mais amplo, e cujo desenvolvimento deve ser atrelado a situações didáticas planejadas ao longo de toda a educação básica, de modo a possibilitar aos alunos revisitar de forma reflexiva seus conhecimentos e sua compreensão acerca do mundo em que vivem (BRASIL, 2017, p. 320).

De acordo com Strieder e Watanabe (2018), a realização de atividades investigativas é defendida desde meados do século XIX, quando as disciplinas científicas passaram a integrar os currículos escolares, e tem sido recomendada, 
há longa data, pelas publicações da área de Ensino de Ciências e pelos documentos oficiais da área.

Neste artigo, destacamos o trabalho de Carvalho (2016) que propõe a criação de um ambiente investigativo nas aulas de Ciências por meio de sequências de ensino investigativo $(\mathrm{SEI})^{2}$, para proporcionar aos alunos condições de apresentar seus conhecimentos prévios sobre determinada questão, e através do debate com seus colegas e com o professor, compreender o conhecimento científico já estruturado sobre a questão proposta.

Segundo Carvalho (2016), uma SEI deve ser constituída das seguintes atividades-chave: apresentação de um problema para os alunos; sistematização do conhecimento construído pelos alunos; e contextualização do conhecimento relacionado ao problema proposto.

Em contraposição ao modelo de ensino diretivo, no qual o professor apresenta o problema, as hipóteses e o plano de trabalho a ser executado pelo aluno semelhante a um receituário em que cabe ao aluno entender o raciocínio do professor - Carvalho (2018) ressalta a participação ativa do aluno no ensino por investigação.

Para que o aluno participe ativamente do processo investigativo, Carvalho (2018) enfatiza a importância de o problema proposto pelo professor ser apresentado adequadamente, a fim de desencadear o raciocínio dos alunos que, com liberdade intelectual,

[...] terão coragem de expor seus pensamentos, seus raciocínios e suas argumentações. [...] Esses dois conceitos - liberdade intelectual e elaboração de problemas - são essenciais para o professor criar condições em sala de aula para os alunos interagirem com o material e construírem seus conhecimentos em uma situação de ensino por investigação (CARVALHO, 2018, p. 767).

Unificando os potenciais pedagógicos das brincadeiras e das atividades investigativas, demonstrados por vários estudiosos, elaboramos uma estratégia de ensino denominada brincadeiras científicas investigativas $(\mathrm{BCl})$. Neste artigo analisamos a participação de uma criança do quinto ano do Ensino Fundamental em uma dessas $\mathrm{BCl}$.

\section{BRINCADEIRAS CIENTÍFICAS INVESTIGATIVAS (BCI)}

As brincadeiras científicas investigativas $(\mathrm{BCl})$ são atividades de investigação do princípio de funcionamento de brinquedos científicos ${ }^{3}$ que aproveitam o potencial pedagógico das brincadeiras e das atividades investigativas para explorar fenômenos físicos na Educação em Ciências nos anos iniciais do Ensino Fundamental ${ }^{4}$.

As $\mathrm{BCl}$ são realizadas em sete momentos, englobando tanto as atividadeschave de uma SEl, propostas por Carvalho (2016), quanto as ações a serem estimuladas pelo ensino de Ciências nos alunos do Ensino Fundamental, propostas pela BNCC, procurando incentivar as crianças a assumirem o protagonismo em uma atividade investigativa norteada por uma brincadeira. Nessa perspectiva, o 
protagonismo do professor fica limitado ao primeiro momento da atividade, ou seja, na proposição da BCl (Quadro 1).

Quadro 1 - Estrutura das brincadeiras científicas investigativas (BCI)

\begin{tabular}{|c|c|}
\hline Momento & Descrição \\
\hline 1 은 & Proposição da $\mathrm{BCl}$ \\
\hline 20 & Apresentação de hipóteses sobre o funcionamento do brinquedo \\
\hline 3으 & Testando as hipóteses sobre o funcionamento do brinquedo \\
\hline 4 운 & Descrição do brinquedo \\
\hline 5 우 & Construção do brinquedo \\
\hline 60 & Brincando com o brinquedo \\
\hline 70 & Socialização do brinquedo \\
\hline
\end{tabular}

Fonte: Adaptado de Eiras (2019).

A $\mathrm{BCl}$ começa com a proposição de um problema relacionado ao funcionamento de um brinquedo científico com o objetivo de estimular as crianças a participarem de uma investigação. Nos 2ㅇ, 3으 e 4ㅇ momentos, ocorre, sequencialmente, a sistematização do conhecimento pelas crianças a partir da apresentação de hipóteses sobre o funcionamento do brinquedo, o teste dessas hipóteses por meio da manipulação do brinquedo, e a descrição do funcionamento do brinquedo, individualmente e em grupo. Nos 5ㅇ, 6ㅇ e 7을omentos, acontece a contextualização do conhecimento por meio da construção do brinquedo, a intervenção da criança, na busca de soluções para o seu funcionamento satisfatório e para sua utilização em brincadeiras, e a socialização do brinquedo com outras pessoas para além do contexto escolar.

Eiras (2019) analisou a participação de crianças em brincadeiras científicas investigativas $(\mathrm{BCl})$ realizadas durante as aulas de Ciências nos anos iniciais do Ensino Fundamental. A pesquisa foi desenvolvida numa abordagem qualitativa (LÜDKE; ANDRÉ, 1986, BOGDAN; BIKLEN, 1994), na perspectiva histórico-cultural, (FREITAS, 1996, 2007, 2010), em uma turma de quinto ano do Ensino Fundamental de uma escola pública municipal de Juiz de Fora, Minas Gerais, constituída por 15 crianças com idades entre 9 e 12 anos.

Neste artigo, destacamos um episódio específico, analisando a participação de uma das crianças da turma investigada, de pseudônimo Lúcia, em uma $\mathrm{BCl}$ que problematizou o funcionamento de um brinquedo denominado disco flutuante. A atividade foi desenvolvida por Eiras (2019) com o auxílio da professora de Ciências da turma investigada, de pseudônimo Paula, na observação e coleta de dados. Os dados foram obtidos pela observação de toda a prática da atividade, por meio de conversas informais com Lúcia e com a professora Paula, além de registros audiovisuais da $\mathrm{BCl}$ analisada. Para isso, foram observados todos os procedimentos éticos da pesquisa, que foi aprovada pelo Comitê de Ética de Pesquisa (CEP) da instituição do primeiro autor. 


\section{$\mathrm{BCl}$ - O DISCO FLUTUANTE}

A $\mathrm{BCl}$ com o disco flutuante foi desenvolvida em quatro aulas de Ciências, organizadas em módulos geminados em duas semanas consecutivas, totalizando 160 minutos.

No 1 o momento da $\mathrm{BCl}$ foi feita a apresentação de uma história de faz-deconta (HFC) com o objetivo de enriquecer a imaginação das crianças e criar condições para a realização da atividade. Nesse contexto entendemos que não é somente "[...] a imaginação que determina a ação, mas são as condições da ação que tornam necessária a imaginação e dão origem a ela" (LEONTIEV, 2017, p. 127).

De forma resumida, o enredo da HFC relatava a invasão da Terra, em 2023, por alienígenas, denominados de D3, provenientes do planeta Alien. Os alienígenas D3 invadiram a Terra interessados no ar, na água e nas fontes de energia do planeta. Após dois anos de guerra, os humanos venceram os invasores, mas a Terra ficou com poucas fontes de energia e com a água e o ar poluídos e contaminados. $\mathrm{O}$ ar foi contaminado com o vírus Microfix que infectou os adultos, eliminando todo o conhecimento que eles possuíam sobre Ciências. Somente as crianças foram poupadas. Além disso, todos os livros, computadores e a Internet foram destruídos na guerra. Nesse panorama pós-guerra, o pesquisador personificou um construtor de brinquedos, infectado pelo vírus Microfix, que necessitava do auxílio das crianças para compreender o funcionamento dos brinquedos que ele construía.

As crianças participaram com muito interesse da construção da HFC, sugerindo nomes para os alienígenas, para o planeta deles e para o vírus que infectou os adultos.

O brinquedo apresentado nesta $\mathrm{BCl}$ foi o disco flutuante (DF), cujo objetivo é explorar fenômenos físicos relacionados ao movimento. O disco flutuante é construído com um CD (compact disc) usado, um balão (bexiga de borracha de festa de criança), uma tampa de garrafa PET furada no centro, uma seringa de plástico de $5 \mathrm{ml}$ e um elástico látex fino $\mathrm{n}$ ㅇ 18 (MENEZES, et al., 2016). O balão é fixado, com o auxílio do elástico, no pedaço da seringa. Esse dispositivo é inflado com ar e depois é inserido no furo da tampa de garrafa PET, previamente colada no centro do CD (ver sequência da Figura 1). O disco flutuante é então colocado sobre uma superfície horizontal lisa e com um leve toque ele entra em movimento com muita facilidade. Isso ocorre porque o ar proveniente da bexiga, ao escapar pela parte inferior do brinquedo, forma uma camada entre o $C D$ e a superfície de apoio, diminuindo o atrito. 
Figura 1 - Disco flutuante

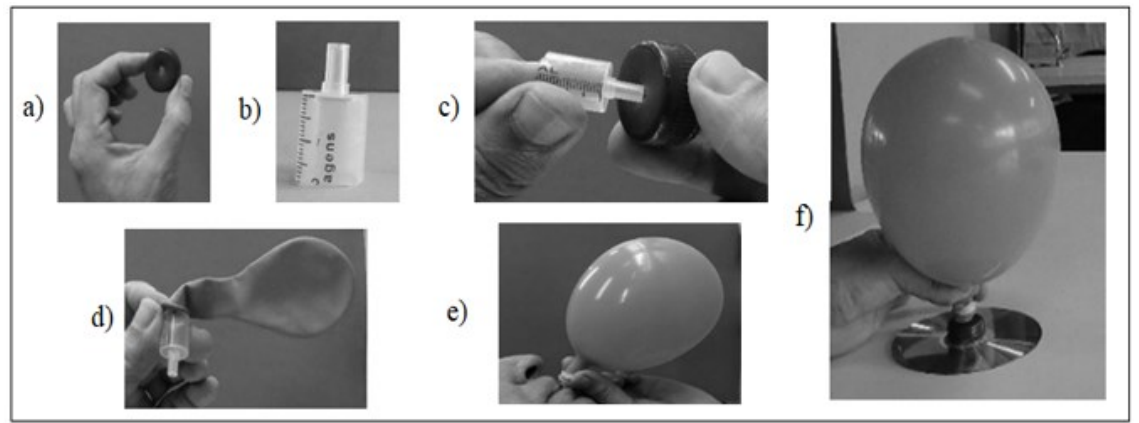

a) tampa de garrafa PET com furo; c) inserindo o bico da seringa na tampa; e) enchendo o balão;

b) pedaço de seringa de $5 \mathrm{ml}$; d) prendendo o balão na seringa; f) disco flutuante.

Fonte: Adaptado de Menezes, et. al. (2016).

Inicialmente dois brinquedos, aparentemente iguais, foram construídos e mostrados para as crianças. Porém, em um deles (DF1) a saída de ar do bico da seringa foi interrompida e foi feito um furo lateral na seringa para que o ar do balão escapasse pela saída (Figura 2).

Figura 2 - Disco flutuante

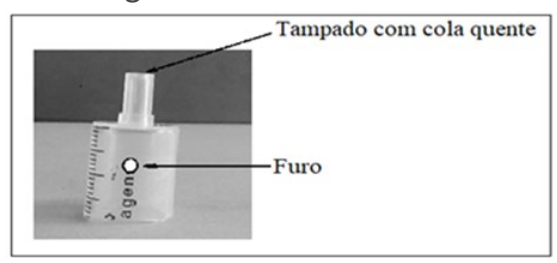

Fonte: Eiras (2019).

O outro disco (DF2) foi construído normalmente seguindo os passos indicados na Figura 1.

As crianças foram convidadas a observar o que acontecia com os dois brinquedos após os balões serem cheios de ar e os discos lançados sobre o piso da sala.

O primeiro brinquedo (DF1) ao ser lançado, apesar de o volume do balão diminuir devido à saída lateral do ar, rapidamente retornava ao repouso. Nesse momento observou-se um certo descontentamento das crianças, pois elas esperavam ser surpreendidas com algo inusitado.

Em meio àquele cenário de descontentamento, o segundo brinquedo (DF2) foi lançado sobre a superfície do piso da sala. Por ter sido construído de forma adequada, o ar proveniente do interior do balão era expelido pelo bico da seringa, formando uma camada entre a superfície do $C D$ e o piso, o que facilitava o movimento do disco.

Ao observarem a facilidade do movimento do segundo brinquedo (DF2), as crianças demonstraram surpresa e alegria. Várias delas, entusiasmadas com o fenômeno, queriam pegar aquele objeto misterioso para ver porque ele se comportava daquela maneira. Entretanto, antes de explorar o brinquedo elas foram incentivadas a apresentar suas hipóteses sobre o funcionamento do segundo disco flutuante (DF2), caracterizando o 2 ㅇ Momento da $\mathrm{BCl}$. 
As crianças enunciaram suas hipóteses livremente e o pesquisador não avaliava se as hipóteses estavam corretas ou não, apenas preocupava-se em evidenciar a questão proposta para incentivar a investigação do princípio de funcionamento do disco flutuante.

Apesar de as crianças estarem participando ativamente da brincadeira investigativa, uma menina - que aqui iremos chamar de Lúcia - chamou a atenção do pesquisador. Lúcia já havia afirmado em aulas anteriores que não gostava de estudar Ciências, e permanecia com a cabeça deitada sobre a sua mesa na maior parte do tempo, demonstrando desinteresse pelo que era ensinado. A partir da proposição da $\mathrm{BCl}$, Lúcia mostrou-se bastante envolvida com a atividade e depois de muito observar o disco flutuante, apresentou sua hipótese de que era a face do $C D$ em contato com a superfície da sala que influenciava o seu movimento. Segundo ela, o brinquedo (DF1) não movimentava com facilidade porque "[...] o lado dele cheio de escritos, agarra".

A hipótese de Lúcia era uma tentativa de explicar a diferença entre os movimentos do DF1 e do DF2, pois no caso do DF2 era o lado brilhante, sem escritos, que ficava em contato com o piso da sala. A escolha dos lados que ficariam em contato com o piso da sala foi feita de forma proposital pelo pesquisador a fim de incentivar as crianças a pensarem que isso poderia exercer influência no comportamento do brinquedo.

Lúcia manteve seu interesse solicitando que os brinquedos fossem lançados diversas vezes para tentar compreender o porquê de um deles se movimentar com facilidade e ou outro não ( 3 o momento da $\mathrm{BCl}$ ). Não satisfeita com o resultado de suas observações, ela solicitou a troca das seringas e dos balões para poder verificar se era, de fato, o lado do CD que interferia no movimento do brinquedo. De acordo com a hipótese de Lúcia, o lado brilhante em contato com o piso da sala facilitaria o movimento do brinquedo.

Após realizada a troca solicitada por Lúcia, o brinquedo foi lançado novamente e, para espanto dela e das outras crianças, ele continuava movendo com dificuldade, tal como o disco flutuante (DF2). Apesar do desapontamento de Lúcia por não ter descoberto o que provocava a diferença do movimento dos dois discos, ela pareceu continuar investigando o mistério daquele brinquedo.

Antes de as crianças serem autorizadas a manipular o brinquedo, foi solicitado a elas que desenhassem e/ou escrevessem sobre o funcionamento do brinquedo (40 momento da $\mathrm{BCl}$ ). Para registrar sua ideia, cada criança recebeu uma folha de papel com a seguinte orientação: "Escreva ou desenhe como você acha que o brinquedo funciona".

Naquele momento, os brinquedos foram dispostos sobre uma mesa na frente da sala e as crianças não foram diretamente incentivadas e nem impedidas de manipulá-los. A ideia era observar como elas agiriam na tentativa de explicar o funcionamento do disco flutuante.

Lúcia, espontaneamente, levantou-se de sua cadeira, foi até a mesa e pegou os brinquedos (DF1 e DF2) para poder observar as características de cada um. Na sequência, ela pegou a seringa do DF2, encheu o balão de ar e observou o seu esvaziamento. Depois pegou a seringa do DF1, comparou com a seringa do DF2 e concluiu que uma delas estava furada (DF1) e a outra não (DF2), expressando em sua face que havia descoberto algo (Figura 3). 
Figura 3 - Lúcia investigando os discos flutuantes

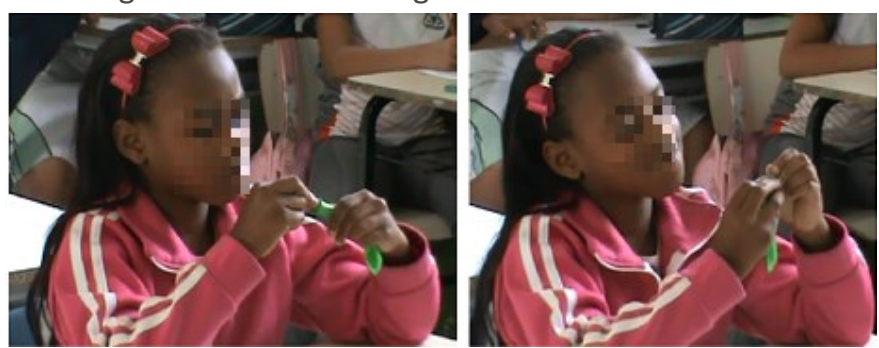

Fonte: Eiras (2019).

Feliz com a descoberta, Lúcia fixou o balão novamente na seringa do DF1, mas agora com o balão cobrindo seus furos laterais. Entretanto, na tentativa de encher o balão, soprando pela seringa, ela não logrou êxito. Depois de tentar por várias vezes, Lúcia levantou-se, explicou ao pesquisador o que havia feito, e solicitou auxílio.

Foi explicado para Lúcia que o bico da seringa do DF1 estava tampado com cola quente. É por isso que ela não conseguia encher o balão para testar sua segunda hipótese, de que o brinquedo moveria com facilidade tampando-se os furos laterais da seringa com o balão. Lúcia, entusiasmada, solicitou que outra seringa com furos laterais, mas com o bico desobstruído, fosse providenciada. Com essa nova seringa, ela encheu o balão, de forma que os furos laterais ficassem tampados por ele, fixou o novo dispositivo no CD e lançou o novo brinquedo sobre a superfície do piso da sala.

Ao observarem o brinquedo movimentar com facilidade, as outras crianças ficaram entusiasmadas e mostraram-se surpresas. Várias delas parabenizaram Lúcia, que se mostrou orgulhosa e valorizada.

Naquele ambiente rico em ludicidade, um outro aluno, aqui denominado de Geraldo, sugeriu que fosse feita uma corrida de discos flutuantes na aula da próxima semana, pois aquela já estava terminando. Enquanto o pesquisador aceitava a sugestão do Geraldo, Lúcia aproximou-se e, espontaneamente, explicou o funcionamento do disco flutuante, indicando a saída do ar do balão pela parte de baixo do CD como o motivo da facilidade do seu movimento.

$\mathrm{Na}$ semana seguinte a $\mathrm{BCl}$ foi retomada. Antes da construção do disco flutuante pelas crianças, foi realizada a corrida dos discos flutuantes, sugerida pelo Geraldo na aula anterior (5ㅇ momento da $\mathrm{BCl})^{5}$. Para realização da brincadeira as crianças foram organizadas em grupos com três participantes. Cada grupo recebeu um disco flutuante para ser analisado e modificado para que percorresse a maior distância possível, após ser lançado sobre uma superfície plana horizontal formada por várias mesas alinhadas.

Lúcia, ao receber o disco flutuante do seu grupo, encheu o balão de ar e brincou de lançá-lo sobre a mesa para uma colega do grupo. A partir de certo momento, Lúcia examinou o brinquedo cuidadosamente de vários ângulos, por baixo, por cima, encheu o balão, observou a saída do ar e passou a mão na superfície do CD que iria ficar em contato com a superfície da mesa como se a estivesse limpando. Posteriormente, com o balão cheio de ar, lançou o disco flutuante sobre a mesa e pareceu satisfeita com o resultado obtido. 
Após a brincadeira da corrida, cada criança recebeu o material necessário para a construção do seu próprio brinquedo (6o momento da $\mathrm{BCl}$ ). Lúcia, após ter construído o seu disco flutuante, perguntou o que aconteceria com o brinquedo se o balão fosse cheio de água, ao invés de ar. Várias crianças apresentaram suas hipóteses sobre o que aconteceria, inclusive Lúcia que se mostrou ansiosa em testar a sua ideia em casa.

Na semana seguinte, antes da realização de uma outra $\mathrm{BCl}$, o pesquisador perguntou se as crianças haviam mostrado o disco flutuante para outras pessoas (7ㅇ momento da $\mathrm{BCl}$ ). Várias delas balançaram a cabeça afirmativamente, inclusive Lúcia que contou ter mostrado o brinquedo para seus familiares. Ela também relatou ter construído um outro disco flutuante para sua prima para que pudessem brincar de corrida. Além disso, Lúcia disse ter explicado para seus familiares que era o ar que saía pela parte de baixo do CD que facilitava movimento do brinquedo. Perguntada se havia testado o disco flutuante com água ao invés de ar, ela respondeu que sim, explicando que com água não deu certo, pois o balão ficava muito pesado.

Conforme já relatado, a $\mathrm{BCl}$ foi estruturada em sete momentos para incentivar as crianças a assumirem o protagonismo da atividade, cabendo ao professor apenas a mediação da atividade.

\section{O PROTAGONISMO INFANTIL}

Para Sarmento (2004, p.3), durante grande parte da Idade Média, "as crianças foram consideradas como meros seres biológicos, sem estatuto social nem autonomia existencial". Corsaro $(2011$, p.18) considera que, em decorrência do status de subordinação nas sociedades, "[...] é comum que os adultos vejam as crianças de forma prospectiva, isto é, em uma perspectiva do que se tornarão futuros adultos, com um lugar na ordem social e as contribuições que a ela darão". De acordo com esse autor, o processo de socialização da criança apoia-se em dois modelos teóricos: o determinista, em que a criança é considerada um sujeito iniciante e passivo, que deve receber um treinamento cuidadoso para se tornar um adulto capaz; e o construtivista, que considera a criança um sujeito ativo que aprende e constrói seu mundo social e seu lugar nele (CORSARO, 2011).

Atualmente, apesar de o modelo construtivista ser hegemônico na maioria das escolas brasileiras, as atividades realizadas nas aulas de Ciências nos anos iniciais do Ensino Fundamental ainda apresentam nuances da concepção determinista, na qual a criança desempenha um papel passivo no processo educacional ou, quando muito, na execução de ações obedientes e dependentes das orientações do professor.

Nos estudos sobre a participação das crianças em atividades diversas, vários autores nomeiam a criança como protagonista para caracterizar suas ações em determinada atividade (FRIEDMANN, 2017; SARAMAGO, 2005). De acordo com Friedmann (2017), a palavra protagonista é derivada do grego protagonistés (protos que significa "principal" ou "primeiro" e agonistes que significa "lutador" ou "competidor"), sendo muito usada no teatro e no cinema para se referir à pessoa que desempenha ou ocupa o papel principal em um acontecimento. No nosso entendimento, $\mathrm{o}$ ato de ocupar o papel principal em um acontecimento ou 
atividade pode acontecer de várias formas, como por exemplo, numa atividade educacional de Ciências em que uma criança pode ser protagonista da atividade executando ações obedientes, conforme as orientações do seu professor, da mesma forma que o ator principal de uma peça teatral segue o script designado pelo diretor. Por outro lado, neste estudo defendemos que a criança pode ser protagonista de uma atividade de forma autônoma, ou seja, sem a necessidade de uma orientação direta, de um passo a passo designado por seu professor, da mesma forma que um ator quando "quebra" o script traçado para uma peça.

Vários autores da Sociologia da Infância se ocuparam em definir diferentes níveis de participação das crianças em atividades sociais, entre eles: Lansdown (2005); Hart (1992); O'Kane (2013); e Fernandes (2009). Hart (1992), estudioso da infância, propõe a ideia de uma escada de participação, constituída de oito degraus, cada um correspondente a um nível de atuação das crianças, agrupados em dois setores: degraus da não participação e degraus da participação (Figura 4).

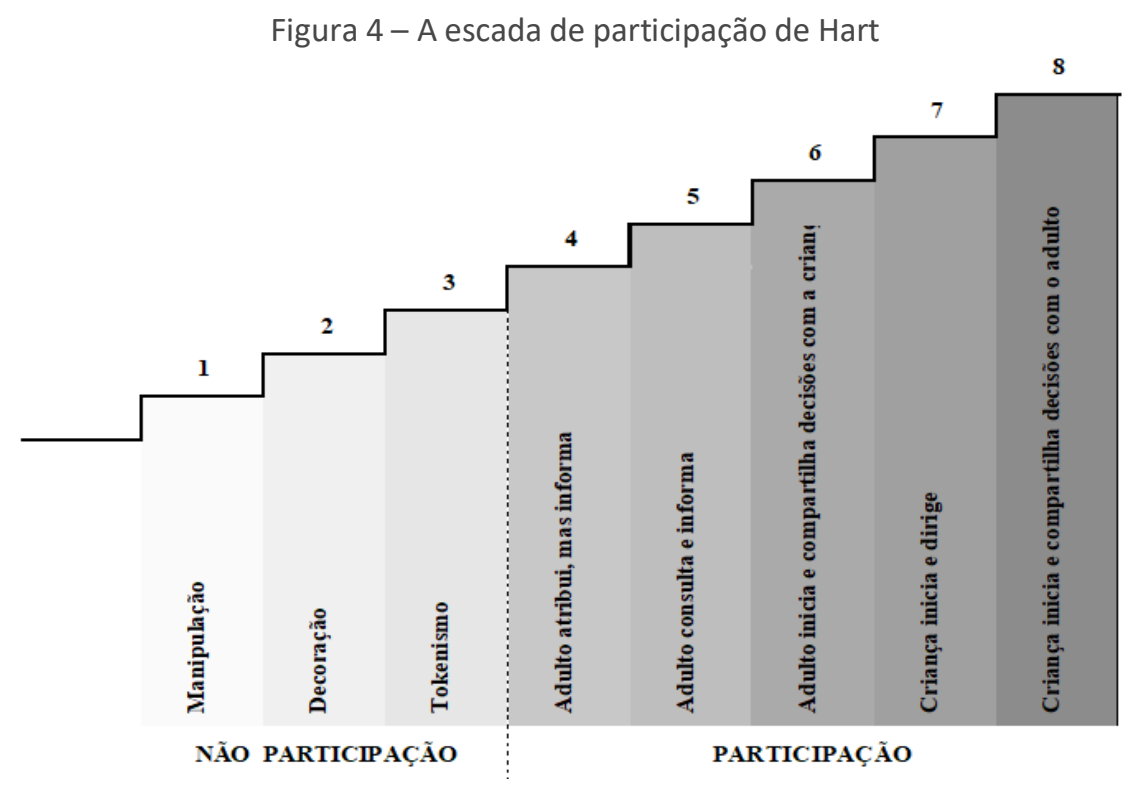

Fonte: Adaptado de HART, 1992, p.8.

O primeiro e segundo degraus da escada de Hart - manipulação e decoração - são referentes a projetos nos quais a "participação" das crianças é totalmente dependente dos adultos, relegando às crianças um papel decorativo. $O$ terceiro degrau - tokenismo ${ }^{6}$ - refere-se a projetos nos quais a "participação" das crianças é aparente, uma vez que a maioria delas não participa, ficando relegado apenas àquelas que têm habilidades pertinentes. De acordo com Hart (1992), no tokenismo, a voz concedida às crianças é ilusória, uma vez que elas não detêm poder de escolha sobre o assunto, de modo que sua oportunidade de formular opiniões é mínima ou inexistente. O quarto degrau - adulto atribui, mas informa refere-se a projetos nos quais os adultos atribuem atividades para as crianças e informam os objetivos. No quinto degrau - adulto consulta e informa -, apesar de os projetos serem dos adultos e realizados por eles, as crianças, em alguns momentos, trabalham como consultores dos adultos, entendendo o processo e tendo suas opiniões tratadas com seriedade. O sexto degrau - adulto inicia e compartilha decisões com a criança - é o nível, de acordo com Hart (1992), em que se inicia a verdadeira participação das crianças. Embora os projetos desse nível 
sejam iniciados por adultos, as tomadas de decisão são compartilhadas com as crianças. O sétimo degrau - criança inicia e dirige - refere-se aos processos iniciados e dirigidos pelas crianças, e o oitavo degrau refere-se aos projetos nos quais a criança inicia e compartilha as decisões com o adulto.

Com base na categorização da escada de Hart (1992), a verdadeira participação das crianças só acontece quando elas participam das tomadas de decisão, sendo consideradas e respeitadas como agentes sociais ativos, construtoras das suas culturas de pares e participantes da produção do mundo adulto.

Na perspectiva de Hart (1992) pode-se considerar que a participação protagonizada, proposta por O'Kane (2013), o patamar do protagonismo, proposto por Fernandes (2009) e o processo autônomo, proposto por Lansdown (2005), correspondem à efetiva participação das crianças por envolverem tomadas de decisão. A partir desses autores e do estudo sobre as $\mathrm{BCl}$ na educação em Ciências, Eiras (2019) definiu dois níveis de protagonismo: o protagonismo orientado quando a criança ocupa o papel principal em um acontecimento, a partir da orientação direta do adulto ou do sujeito que a instrui - e o autônomo - quando a criança exerce o papel principal num acontecimento, independente de uma orientação direta do adulto ou do sujeito que a instrui. Nessa perspectiva, entende-se que o protagonismo orientado é exercido pela criança como resultado de orientações externas, enquanto o protagonismo autônomo é exercido pela criança como um efeito direto da atividade desenvolvida (Eiras, 2019).

\section{ANÁLISE DA BCI - O DISCO FLUTUANTE}

$\mathrm{Na} \mathrm{BCl}$ com o disco flutuante as crianças exerceram tanto o protagonismo orientado quanto o protagonismo autônomo. Analisaremos a seguir o protagonismo autônomo exercido pela aluna Lúcia durante a realização da $\mathrm{BCl}$ descrita neste trabalho.

Com o objetivo de mapear e facilitar a leitura das informações colhidas na pesquisa de campo acerca do protagonismo autônomo de crianças nas $\mathrm{BCl}$, Eiras (2019) definiu como ações autônomas aquelas que acontecem independentes de uma ordem ou orientação direta de um adulto ou de um sujeito mais capaz, ou seja, ações que emergem como fruto da própria atividade desenvolvida, levando a criança ao exercício do protagonismo autônomo. Assim, quando uma criança explica algo sem ser solicitada diretamente; quando constrói um brinquedo a partir de suas próprias ideias, ou quando pergunta algo inusitado, entendemos que ela está exercendo ações autônomas.

O quadro 2, a seguir, apresenta as ações autônomas definidas por Eiras (2019), o descritor e o símbolo correspondente para cada ação. 
Quadro 2 - Ações autônomas

\begin{tabular}{|c|c|c|}
\hline $\begin{array}{c}\text { Ação } \\
\text { autônoma }\end{array}$ & Descritor & Símbolo \\
\hline AFASTAR & Demonstrou desinteresse ou não desejou participar & AF \\
\hline APROXIMAR & Demonstrou interesse ou desejou participar & AP \\
\hline BRINCAR & Brincou individualmente ou coletivamente & BR \\
\hline INVESTIGAR & Investigou ou experimentou & IN \\
\hline ENUNCIAR & Enunciou uma pergunta, ideia, hipótese ou explicação & EM \\
\hline SOCIALIZAR & Socializou com outras pessoas & SO \\
\hline CONSTRUIR & Construiu algo & CO \\
\hline
\end{tabular}

Fonte: Eiras (2019).

Utilizando os símbolos das ações autônomas apresentados no quadro 2, apresentamos a seguir o mapeamento cronológico das ações autônomas de Lúcia em cada momento da $\mathrm{BCl}$ com o disco flutuante (Quadro 3).

Quadro 3 - Mapeamento das ações autônomas de Lúcia na $\mathrm{BCl}$ - Disco Flutuante

\begin{tabular}{|c|c|c|c|c|c|c|c|}
\hline Momento da BCI & \multicolumn{7}{|c|}{ Ações autônomas } \\
\hline 19 & AP & - & - & - & - & - & - \\
\hline 20 & AP & IN & EM & IN & - & - & - \\
\hline 30 & EM & IN & EM & IN & - & - & - \\
\hline 40 & AP & IN & EM & CO & AP & IN & EM \\
\hline 50 & BR & IN & BR & - & - & - & - \\
\hline 60 & EM & - & - & - & - & - & - \\
\hline 70 & SO & CO & BR & EN & IN & EN & - \\
\hline
\end{tabular}

Fonte: Adaptado de Eiras (2019).

A partir do mapeamento das ações autônomas de Lúcia traçamos algumas reflexões sobre o protagonismo autônomo exercido por ela durante o desenvolvimento da $\mathrm{BCl}$ com o disco flutuante.

Como já relatado, antes da realização da primeira $\mathrm{BCl}$, Lúcia mostrava-se desinteressada pelo conteúdo de Ciências, permanecendo a maior parte do tempo com a cabeça deitada sobre a mesa. Todavia, desde a proposição da $\mathrm{BCI}$ Lúcia não se esquivou de participar das atividades propostas, mostrando-se interessada sobre o que iria acontecer.

No quadro 3, podemos perceber que ações autônomas de Lúcia aconteceram em todos os momentos da $\mathrm{BCl}$. A partir da aproximação (AP) para a participação da atividade proposta, a ação de investigar (IN) foi seguida ou precedida da enunciação de uma ideia ou explicação (EN) e o brincar (BR) foi seguido ou precedido do investigar (IN) ou do enunciar (EN).

Quando o disco flutuante foi apresentado e a questão a ser investigada foi enunciada pelo pesquisador, Lúcia exerceu o protagonismo autônomo argumentando, enunciando hipóteses, e sugerindo modificações no brinquedo a 
fim de testar essas hipóteses. Foi o que aconteceu quando apresentou a sua hipótese para o funcionamento do disco flutuante e, logo após, solicitou que o brinquedo fosse lançado novamente para verificar se sua ideia estava correta. Aqui percebe-se a importância de a investigação estar entrelaçada com a brincadeira, pois a motivação para brincar independe do seu resultado (LEONTIEV, 2017).

Ainda não satisfeita, Lúcia manipulou e testou os discos flutuantes para observar o que diferenciava um do outro, até enunciar sua nova ideia. 0 envolvimento de Lúcia com a investigação do funcionamento do brinquedo foi evidenciado quando, mesmo sem ser perguntada, explicou o funcionamento dele. Além disso, Lúcia perguntou e depois experimentou encher o balão do disco flutuante com água, ao invés de ar, para descobrir por si própria o que aconteceria.

Podemos concluir que a atividade de investigar o princípio de funcionamento do disco flutuante incentivou Lúcia a exercitar o protagonismo autônomo, pois promoveu a sua liberdade intelectual para a investigação de um problema (CARVALHO, 2016, 2018). Isso vai ao encontro do que afirma Sasseron (2018) de que um dos principais elementos do ensino por investigação é o papel intelectual ativo dos estudantes.

O protagonismo autônomo também está presente no momento em que Lúcia brinca de lançar o disco flutuante sobre a mesa para outra colega, quando ela observa atentamente o seu movimento e apresenta sua hipótese para o funcionamento do brinquedo. Nesse aspecto, concordamos com Vigotski (2008) que considera a brincadeira como uma importante atividade que impulsiona a ação da criança. $O$ envolvimento de Lúcia nas atividades mediadas pela brincadeira foi explicitado no seu relato de ter brincado de corrida de discos flutuantes com a sua prima, tal como realizado na sala de aula.

A importância das brincadeiras na interação entre as crianças e destas com os adultos é ressaltada por Corsaro (2011) que considera que por meio delas os conhecimentos e as práticas da infância vão sendo gradativamente transformadas em competências e conhecimentos necessários para as crianças participarem do mundo adulto, contradizendo aqueles que consideram a brincadeira apenas como uma atividade para passar o tempo. De acordo com Fortuna (2011, p.68), o brincar é uma atividade fascinante, mas "[...] este mesmo fascínio é responsável, ao menos em parte, pelo desprezo que a acompanha [...] sendo motivo para ironia, ridicularização e franco desprezo não só dela mesma, mas também de quem brinca". Talvez, por isso, apesar da valorização da brincadeira para as crianças na Educação Infantil e em alguns componentes curriculares do Ensino Fundamental, ela é pouco explorada na área de Ciências da Natureza da BNCC (BRASIL, 2017), mesmo que as Diretrizes Curriculares Nacionais Gerais para a Educação Básica (DCN) enfatizem a importância de o Ensino Fundamental recuperar o caráter lúdico da aprendizagem, valorizado na Educação Infantil (BRASIL, 2013).

Do exposto, pode-se perceber que a $\mathrm{BCl}$ foi importante para Lúcia conquistar o seu espaço em sala de aula, pois provocou a elevação de sua autoestima, encorajando-a a exercer, sem receio, o protagonismo autônomo perante as outras crianças, dando um salto além do seu comportamento comum (VIGOTSKI, 2008). Como consequência do protagonismo autônomo exercido por Lúcia, ela foi cada vez mais respeitada e valorizada pelos colegas. Dessa forma, apoiados em 
Saramago (2005), podemos considerar que a BCl constituiu uma forma de construção, afirmação e expressão da identidade social de Lúcia.

Assim, consideramos que o principal resultado do protagonismo autônomo exercido por Lúcia foi capacitá-la a se considerar empoderada, autônoma, habilitada e qualificada no enfrentamento de desafios. Isso foi percebido na atitude de Lúcia em apresentar suas ideias perante as outras crianças, sugerindo modificações nos brinquedos a fim de investigar seu funcionamento, além de propor, ao final de outra $\mathrm{BCl}$, realizada posteriormente, algumas construções inusitadas com os objetos que estavam sobre a mesa, tais como lápis, cola, fita adesiva, entre outros, remetendo a Benjamin (2009) que evidencia a capacidade da criança utilizar objetos de diversas maneiras e em vários contextos.

$\mathrm{Na}$ entrevista realizada com a professora da turma, aqui nomeada como Paula, sobre a influência das $\mathrm{BCl}$ no comportamento de Lúcia, ela relatou que a mudança dessa aluna foi muito evidente:

Lúcia sempre foi muito tímida, nunca foi de se mostrar. Você via que ela tinha
vontade de perguntar, mas ela não se expressava, né? Com o tempo, ela se
soltou muito, ela começou a perguntar, ela começou a participar mais das
aulas, tanto de Ciências, como também das outras disciplinas. A gente
percebeu; os outros professores também perceberam isso (Relato da
professora Paula).

Do exposto, o protagonismo autônomo exercido por Lúcia na BCl com o disco flutuante serviu para incentivá-la a questionar, argumentar, sugerir, idealizar, criar, entre outras ações normalmente exercidas por um sujeito ativo e participativo na sociedade.

\section{ALGUMAS CONSIDERAÇÕES}

O incentivo das crianças a exercerem o protagonismo autônomo nas atividades escolares depende, não exclusivamente, mas potencialmente, do deslocamento do professor do status de proprietário/instrutor do conhecimento para o de observador/facilitador das atividades de aprendizagem em sala de aula. Esse deslocamento acontece nas pequenas, mas importantes, ações do professor na proposição e na orientação das atividades a serem realizadas pelas crianças; no incentivo à participação delas; na enunciação e na resolução de uma questão, entre outras.

A estrutura das $\mathrm{BCl}$ ajuda a promover o deslocamento do protagonismo do professor - que acontece apenas no primeiro momento, quando da proposição da atividade - para a criança. Nos momentos subsequentes, a criança ocupa o protagonismo da atividade, independente da orientação do professor, ou seja, ela é estimulada a agir de forma autônoma e criativa, cabendo ao professor o papel de observador, facilitador e incentivador de ações que a levem a sentir-se capaz de realizar a atividade proposta, reforçando sua disposição de continuar participando ativamente do processo de sua própria aprendizagem.

Julgamos pertinente ressaltar que, apesar de a ludicidade ser uma característica importante em atividades escolares realizadas com crianças, ela não é suficiente por si só para promover o envolvimento da criança com o objeto do conhecimento. Cabe ao professor explorar seu potencial pedagógico para alcançar 
os objetivos desejados, entre os quais destacamos o de incentivar o protagonismo autônomo das crianças. Quando uma atividade lúdica é realizada no formato de jogos, por exemplo, as crianças podem ficar submetidas somente às regras rígidas do jogo, não ultrapassando os limites do protagonismo orientado. De modo contrário, quando a atividade lúdica é realizada no formato de brincadeira, tal como nas $\mathrm{BCl}$, as regras mais flexíveis e centradas nas crianças permitem que elas ajam com mais liberdade, apropriando-se do protagonismo autônomo.

Ainda hoje, grande parte das atividades escolares realizadas no Ensino Fundamental está impregnada do modelo determinista de socialização da criança, questionado por Saramago (2005), em que a criança atua em conformidade com as normas e regras definidas pelos adultos, a fim de moldá-la e treiná-la de acordo com um padrão definido, relegando-a a um papel passivo. Nessa perspectiva, quando muito, a ação da criança fica restrita ao exercício do protagonismo orientado, respondendo aos comandos do professor a fim de seguir os passos designados para a obtenção de uma nota satisfatória.

Na sociedade contemporânea, torna-se cada vez mais urgente provocar o deslocamento da criança de sujeito autômato para sujeito autônomo na realização das atividades escolares, visto que a geração do futuro é reflexo da formação recebida hoje.

Esperamos que este artigo sirva de inspiração para pesquisadores e professores ao estudo e à proposição de atividades educacionais que considerem as crianças como sujeitos autônomos, capazes e produtoras de conhecimento e de cultura. 


\title{
Playing, investigating and learning science in early years of elementary school with investigative scientific play
}

\begin{abstract}
In this article we present part of the results of a research that analysed children participation in scientific research games at science classes in the fifth year of Brazilian Elementary School. These games investigate the performance of toys, built by children with low-cost materials, to explore some physical phenomena in Science Education. In this study, we highlight the participation of one child who interacts with a toy called floating disk. The research was conducted by a qualitative approach, in a historical-cultural perspective. Data were obtained through observation of classes and informal conversations with the child and his science teacher. Audiovisual records of the game were also made. The results indicate that this methodology encouraged the child to exercise autonomy in independent actions, such as: to play, investigate, ask questions, raise hypotheses, or give unusual explanations, idealize and build things, and share his ideas with other people. Therewith, we highlight the importance of scientific research games to promote and encourage children's autonomous role. Finally, we understand that the act of taking on the main role of an event, with autonomy and responsibility, is fundamental to the formation of citizens in the contemporary world.
\end{abstract}

KEYWORDS: Scientific Research Games. Science Education. Elementary School. Children's Autonomous Role. 


\section{NOTAS}

1 Crianças de até seis ou sete anos de idade (VIGOTSKI, 2008).

2 Carvalho (2018) mostra a importância em nomear a SEl como ensino investigativo, ao invés de sequência de ensino investigativa, pois, segundo a autora, um ensino investigativo vai muito além das atividades investigativas escritas para os alunos.

3 Construídos com materiais de baixo custo e fácil aquisição para explorar fenômenos físicos na Educação em Ciências no Ensino Fundamental.

$4 \mathrm{Em}$ regra, os anos iniciais são para estudantes de seis a dez anos de idade (do 1 o ao 5 ano) e os anos finais para estudantes de onze a quatorze anos (do 60 ao 9 응 ano) (BRASIL, 2013).

$5 \mathrm{~A}$ sequência de realização do 5 ㅇ e 60 momentos foi alterada para o acolhimento da corrida de discos flutuantes proposta por Geraldo na aula anterior.

6 A expressão tokenismo deriva do termo inglês token, que significa símbolo. Consiste na prática de fazer publicamente pequenas concessões a um grupo minoritário, tão somente para ocultar eventuais acusações de preconceito ou discriminação.

\section{AGRADECIMENTOS}

Agradecemos ao Programa de Pós-Graduação da Faculdade de Educação da Universidade Federal de Juiz de Fora e ao Instituto Federal do Sudeste de Minas Gerais, pelas condições e pelo incentivo para o desenvolvimento deste estudo e à FAPEMIG, pelo apoio financeiro.

\section{REFERÊNCIAS}

BENJAMIN, W. Reflexões sobre a criança, o brinquedo e a educação. Tradução de Marcus Vinícius Mazzari. 2. ed. São Paulo: Duas Cidades, 2009.

BOGDAN, R. C.; BIKLEN, S. K. Investigação qualitativa em educação: uma introdução à teoria e aos métodos. Porto: Porto Editora, 1994.

BRASIL. Estatuto da criança e do adolescente: Lei federal no 8069, de 13 de julho de 1990. Rio de Janeiro: Imprensa Oficial, 2002.

BRASIL. Ministério da Educação. Secretaria de Educação Básica. Diretrizes Curriculares Nacionais Gerais da Educação Básica. Brasília: MEC, 2013. Disponível em:

http://portal.mec.gov.br/index.php?option=com_docman\&view=download\&alias =15548-d-c-n-educacao-basica-nova-pdf\&category_slug=abril-2014pdf\&Itemid=30192. Acesso em: 10 ago. 2015. 2017. Disponível em: http://basenacionalcomum.mec.gov.br/imagens/BNCC 20dez_site.pdf. Acesso em: 05 jan. 2018. 
CARVALHO, A. M. P. O ensino de ciências e a proposição de sequências de ensino investigativas. In: (Org.) Ensino de Ciências por investigação: condições para implementação em sala de aula. São Paulo: Cencage Learning. p.1-20, 2016.

CARVALHO, A. M. P. Fundamentos teóricos e metodológicos do ensino por investigação. Revista Brasileira de Pesquisa em Educação em Ciências, São Paulo, v. 18, n.3, p. 765-794, 2018.

CORSARO, W. A. Sociologia da infância. 2. ed. Porto Alegre: Artmed, 2011.

EIRAS, W. C. S. Protagonismo autônomo de crianças por meio de brincadeiras científicas investigativas na Educação em Ciências nos Anos Iniciais do Ensino Fundamental. 2019. 270 f. Tese (Doutorado em Educação) - Universidade Federal de Juiz de Fora, Minas Gerais, 2019.

FERNANDES, N. Infância e direitos: participação das crianças nos contextos de vida: representações, práticas e poderes. 2009. Tese (Doutorado em Sociologia) Universidade do Minho, Porto, 2009. Disponível em:

http://hdl.handle.net/1822/6978. Acesso em: 5 mar. 2018.

FORTUNA, T. R. A formação lúdica docente e a universidade: contribuições da ludobiografia e da hermenêutica filosófica. 2011. Tese (Doutorado em Educação) - Universidade Federal o Sul do Rio Grande, Porto Alegre, 2011.

FREITAS, M. T. A. A perspectiva sócio-histórica: uma visão humana da construção do conhecimento. In: FREITAS, M. T. A.; SOUZA, S. J.; KRAMER, S. Ciências Humanas e Pesquisa: Leituras de Mikhail Bakhtin. 2. ed. São Paulo: Cortez, 2007.

FREITAS, M. T. A. Bakhtin e a psicologia. In: FARACO, C. A. et al. Diálogos com Bakthin. Curitiba: Editora da UFPR, 1996, p. 165-187.

FREITAS, M. T. A. Discutindo sentidos da palavra intervenção na pesquisa de abordagem histórico-cultural. In: FREITAS, M. T. A.; RAMOS, B. S. (Orgs). Fazer pesquisa na abordagem histórico-cultural: metodologias de construção. Juiz de Fora: Editora UFJF, 2010, p. 25-35. 196p.

FRIEDMANN, A. Protagonismo infantil. In: LOVATO, A.; YIRULA, C. P.; FRANZIM, R. (Orgs.). Protagonismo: a potência de ação da comunidade escolar. 1. ed. São Paulo: Ashoka/Alana, 2017, p. 42-45.

HART, R. A. Children's participation from tokenism to citizenship. Itália: UNICEF, 1992.

LANSDOWN, G. ¿'Me haces caso? El derecho de los niños pequeños a participar en las decisiones que los afectan. Cuadernos sobre Desarrollo Infantil Temprano, 36, 2005.

LEONTIEV, A. N. Os princípios psicológicos da brincadeira pré-escolar. In: VYGOTSKY, L. S.; LURIA, A. R.; LEONTIEV, A. N. Linguagem, desenvolvimento e aprendizagem. 15. ed. São Paulo: Ícone, 2017, p. 119- 142. 
LÜDKE, M.; ANDRÉ, M. E. D. A. Pesquisa em Educação: abordagens qualitativas. São Paulo: E.P.U., 1986. 100 p.

MENEZES et al. Ensino de ciências com brinquedos científicos. São Paulo: Livraria da Física, 2016. 68 p.

O'KANE, C. Children's participation in the analysis, planning and design of programmes: a guide for save the children staff. 2013. Disponível em: http://www.unicef.org/adolescence/cypguide/files/Children_Participation_in_Pr ogramming_Cycle.pdf. Acesso em: 5 mai. 2018.

PRESTES, Z. A brincadeira de faz de conta como atividade-guia. Prefeitura Municipal de Florianópolis, Florianópolis, 2011. Disponível em: http://portal.pmf.sc.gov.br/arquivos/arquivos/pdf/14_02_2011_11.23.25.552343 9fc322d424a19c109abd2d2bb9.pdf. Acesso em: 20 jun. 2016.

SARAMAGO, S. S. S. O protagonismo das crianças. 2005. Tese (Doutorado em Sociologia) - Instituto Superior de Ciências do Trabalho e da Empresa, Lisboa, 2005. Disponível em: https://repositorio.iscte-inl.pt/handle/10071/2368. Acesso em: 07 jun. 2018.

SARMENTO, M. J. As culturas da infância nas encruzilhadas da 2aㅡ modernidade. In: SARMENTO, M. J.; CERISARA, A. B. Crianças e miúdos: perspectivas sociopedagógicas na infância e educação. Porto Alegre, Portugal: Edições ASA, 2004. p. 1-22.

SASSERON, L. Ensino de ciências por investigação e o desenvolvimento de práticas: uma mirada para a base nacional comum curricular. Revista Brasileira de Pesquisa em Educação em Ciências, São Paulo, v. 18, n.3, p. 1061-1085, 2018.

STRIEDER, R. B; WATANABE, G. Atividades investigativas na educação científica: dimensões e perspectivas em diálogos com o ENCl. Revista Brasileira de Pesquisa em Educação em Ciências, São Paulo, v. 18, n.3, p. 819-849, 2018.

VIGOTSKI, L. S. A brincadeira e o desenvolvimento psíquico da criança. Tradução de Zoia Prestes. Rio de Janeiro: Universidade Federal do Rio de Janeiro. Revista Virtual de Gestão de Iniciativas Sociais, n. 11, pp. 23-36. 2008. Disponível em: http://www.Itds.ufrj.br/gis/anteriores/rvgis11.pdf. Acesso em: 10 mar. 2016. 
Recebido: 14 out. 2019

Aprovado: 27 jan. 2020

DOI: $10.3895 /$ actio.v5n2.10528

Como citar:

EIRAS, W. C. S.; MENEZES, P. H. D.; FLÔR, C. C. C. Brincando, investigando e aprendendo ciências nos anos iniciais do ensino fundamental com brincadeiras científicas investigativas. ACTIO, Curitiba, v. 5, n. 2, p. 1-21,

mai./ago. 2020. Disponível em: <https://periodicos.utfpr.edu.br/actio>. Acesso em: XXX

Correspondência:

Wagner da Cruz Seabra Eiras

Av. Presidente Itamar Franco, n. 2310/1002, São Mateus, Juiz de Fora, Minas Gerais, Brasil.

Direito autoral: Este artigo está licenciado sob os termos da Licença Creative Commons-Atribuição 4.0

Internacional.

(c) (1) 